\title{
HUBUNGAN KUALITAS PELAYANAN KESEHATAN DENGAN KEPUASAN PASIEN PENGGUNA BADAN PENYELENGGARA JAMINAN SOSIAL (BPJS) DI PUSKESMAS MAIWAKABUPATEN ENREKANG
}

\section{The Relationship Between The Quality Of Health Sevices And Patien Satisfaction Of Users Of The Social Security Organizing Body (Bpjs) At The Maiwa Health Center In Enrekang Regency}

\author{
Nurheda ${ }^{1)}$ Usman ${ }^{2)}$ Ayu Dwi Putri Rusman ${ }^{3)}$ \\ ${ }^{1)}$ Mahasiswa Konsentrasi Administrasi Kebijakan Kesehatan Fakultas Ilmu Kesehatan \\ Universitas Muhammadiyah Parepare \\ ${ }^{2)}$ Dosen Program Studi Kesehatan Masyarakat Universitas Muhammadiyah Parepare \\ 3) Dosen Program Studi Kesehatan Masyarakat Universitas Muhammadiyah Parepare \\ (edanurheda172@gmail.com)
}

\begin{abstract}
ABSTRAK
Kualitas pelayanan merupakan suatu bentuk penilaian pasien terhadap tingkat pelayanan yang diterima dengan tingkat layanan yang diharapkan. Penelitian ini bertujuan mengetahui hubungan antara kualitas pelayanan kesehatan dengan kepuasan pasien pengguna BPJS yang berkaitan dengan bukti fisik pelayanan, kehandalan pelayanan, tanggapan pelayanan, jaminan pelayanan, dan emphaty pelayanan, di Puskesmas Maiwa Kabupaten Enrekang. Kepuasan adalah suatu tingkat perasaan pasien yang timbul sebagai akibat dari kinerja layanan kesehatan yang diperoleh setelah pasien membandingkan tentang apa yang harapkan. Untuk memperoleh data dilakukan wawancara dengan menggunakan kuesioner dengan 95 responden yang ditentukan dengan teknik accidental sampling. Hasil penelitian menunjukan bahwa adanya hubungan antara kualitas pelayanan kesehatan dengan kepuasan pasien BPJS dimana bukti fisik pelayanan $p(0,001)$, kehandalan pelayanan $p(0,402)$, daya tanggap pelayanan $p(0,008)$, jaminan pelayanan $p(0,000)$, emphaty pelayanan $p(0,007)$. Bagi pihak Puskesmas Maiwa Kabupaten Enrekang perlu mengembangkan sistem informasi manajemen Puskesmas untuk lebih memudahkan pelayanan serta evaluasi cepat terhadap kebutuhan pelayanan.
\end{abstract}

Kata Kunci : Kualitas Pelayanan Kesehatan, Kepuasan Pasien

\section{ABSTRACT}

Service quality is a form of patient assessment of the level of service received whit the expected level of service. This study aims to determine the relationship between quality of health services with patient satisfaction BPJS users relationg to physical evidence of service, service reliability, service response, service guarentee, and service emphaty, at Maiwa Health Center Enrekang Distruct. Satisfaction is a level of feeling that a patient has as a result of the perfomance of health services obtained after the patient compares what is expected. To obtain data, interviews were conducted using a questonnaire whit 95 respondents determined by accidental sampling technique. The results showed the there was a relationship between quality of health services whit satisfaction of services $p(0,001)$, service reliability $p(0,402)$, service responsiveness $p(0,008)$, service guarantee p(0,000), emphaty service (0,007). For the Maiwa health center, Enrekang Regency has developed a Puskesmas managemen information system to make it easier for services and rapid evaluation of service needs.

Keywords : Quality of health service, patient satisfaction 


\section{PENDAHULUAN}

Kesehatan merupakan kebutuhan dasar manusia untuk dapat hidup layak dan produktif, untuk itu diperlukan penyelenggaraan pelayanan kesehatan yang terkendali biaya dan kualitasnya. Seperti yang tercantum dalam Undang-Undang Nomor 36 Tahun 2009 tentang kesehatan ditegaskan bahwa setiap orang mempunyai hak yang sama dalam memperoleh akses atau sumber daya di bidang kesehatan dan memperoleh pelayanan kesehatan yang aman, bermutu, dan terjangkau. Selain itu dalam Pasal $28 \mathrm{H}$ ayat (1) dinyatakan bahwa "Setiap orang hendak hidup sejahtera lahir dan batin, bertempat tinggal, dan mendapatkan lingkungan hidup yang baik dan sehat serta berhak memperoleh pelayanan kesehatan" dan Pasal 34 ayat (3) "Negara bertanggung jawab atas penyediaan fasilitas pelayanan kesehatan dan fasilitas pelayanan umum yang baik."

$$
\text { Pusat kesehatan masyarakat }
$$

(Puskesmas) sebagai salah satu fasilitas pelayanan kesehatan umum yang memberikan pelayanan secara menyeluruh dan terpadu kepada masyarakat di wilayah kerjanya dalam bentuk kegiatan pokok. Pelayanan Puskesmas yang secara mneyeluruh meliputi pelayanan kuratif (pengobatan), preventif (upaya pencegahan), promotif (peningkatan kesehatan), dan rehabilitatif (pemulihan kesehatan). Pelayanan tersebut ditujukan kepada semua penduduk, dengan tidak membedakan jenis kelamin dan golongan umur, sejak pembuahan dalam kandungan sampai tutup usia. ${ }^{1}$

Dari uraian diatas, maka dapat disimpulkan bahwa puskesmas merupakan sarana kesehatan yang memberikan pelayanan kesehatan dan berperan penting untuk meningkatkan derajat kesehatan masyarakat. Oleh karena itu, penyediaan jasa pelayanan kesehatan seperti puskesmas dituntut untuk memberikan kualitas pelayanan yang baik.

Puskesmas harus memiliki pelayanan kesehatan yang berkualitas sehingga masyarakat mampu hidup sehat dan tujuan pembangunan kesehatan akan tercapai. Terdapat dua pihak yang terlibat dalam pelayanan kesehatan di puskesmas, yaitu pihak memberi pelayanan (Puskesmas) dan pihak penerima pelayanan (pasien).Oleh karena itu baik atau tidaknya kualitas pelayanan kesehatan tidak hanya ditentukan berdasarkan sudut pandang pihak puskesmas, tetapi juga harus melibatkan sudut pandang pasien.

Mengukur kualitas pelayanan kesehatan lebih sulit daripada mengukur kualitas barang. ${ }^{2}$ Konsep kualitas pelayanan yang populer adalah konsep SERVQUAL. Meskipun konsep tersebut sudah berusia lebih dari dua puluh tahun, konsep ini merupakan konsep yang paling banyak digunakan diseluruh dunia dalam hal pelayanan. ${ }^{2}$ Konsep tersebut berisi lima dimensi kualitas pelayanan, yaitu tangible, reliability, responsiveness, assurance, dan empathy. ${ }^{2}$ 
Tanggung jawab penyelenggara untuk meningkatkan kualitas pelayanan semakin besar apabila jumlah penduduk di wilayah kerja semakin besar. Umumnya sasaran penduduk yang dilayani oleh sebuah puskesmas adalah 20.000 penduduk setiap puskesmas. Apabila lebih dari 20.000 penduduk, maka jelas terlihat semakin besar tanggung jawab puskesmas. Misalnya, Puskesmas di kecamatan Maiwa Kabupaten Enrekang yang mempunyai jumlah penduduk 26.512 jiwa.

Setelah berlakunya program Badan Penyelenggara Jaminan Sosial (BPJS) dari pemerintah masyarakat dapat lebih mudah menggunakan pelayanan kesehatan. Pelayanan diberikan dari masyarakat dengan status ekonomi rendah hingga masyarakat dengan status ekonomi tinggi serta pelayanan primer hingga pelayanan sekunder. Namun, setelah setahun program BPJS ini berjalan selalu ada berbagai macam tanggapan dari masyarakat pengguna BPJS. ${ }^{3}$

BPJS Kesehatan mencatat pada tahun 2017 indeks kepuasan peserta sebanyak 79,5\%. Untuk indeks kepuasan fasilitas kesehatan sebesar $89,5 \%$. Sedangkan bila dibandingkan dengan indeks pada 2016, untuk kepuasan peserta sebesar 78,6\% dan fasilitas kesehatan 76,2\% (BPJS Kesehatan, 2017).

Hasil analisis data tingkat kepuasan pengguna kartu BPJS di Kota Makassar didapatkan bahwa responden menyatakan puas sebesar $85 \%$ dan $15 \%$ menyatakan tidak. Untuk dimensi tangibles responden menyatakan puas sebesar $90 \%$ dan $10 \%$ menyatakan tidak puas. Untuk dimensi empaty responden menyatakan puas sebesar $95.5 \%$ dan 7,5\% menyatakan tidak puas.Untuk dimensi realibility responden menyatakan puas sebesar $87.5 \%$ dan $12.5 \%$ menyatakan tidak puas. ${ }^{4}$

Jika suatu instansi kesehatan salah satunya Puskesmas akan melakukan upaya peningkatan mutu pelayanan kesehatan, pengukuran tingkat kepuasan pasien harus dilakukan melalui pengukuran tersebut, dapat diketahui sejauh mana dimensi-dimensi mutu layanan kesehatan yang telah diselenggarakan dapat memenuhi harapan pasien. ${ }^{4}$

Berdasarkan studi pendahulu yang dilakukan peneliti melalui hasil observasi dan wawancara dari beberapa pengguna BPJS di Kecamatan Maiwa bahwa didapatkan bahwa pelayanan yang diterima tidak sama dengan pelayanan yang diberikan kepada pasien umum I non BPJS, Pasien miskin pengguna BPJS mendapat alur adminidtrasi yang terkesan lebih rumit dan lama dibandingkan dengan pasien umum dan non BPJS sehingga pasien merasa kurang puas terhadap pelayanan kesehatan yang diberikan oleh petugas.

Sekitar 70.000 jiwa masyarakat Kabupaten Enrekang belum terdaftar dalam program jaminan kesehatan nasional dari (BPJS), dari sekitar 238.000 jiwa penduduk Kabupaten Enrekang, baru 160.000 jiwa yang sudah terdaftar sebagai peserta BPJS (Dinkes Enrekang, 2017). Berdasarkan identifikasi masalah tersebut maka peneliti tertarik mengambil judul yaitu "Hubungan Kualitas 
Pelayanan Kesehatan dengan Kepuasan Pasien Pengguna Badan Penyelenggara Jaminan Sosial (BPJS) Di Puskesmas Maiwa Kabupaten Enrekang.

\section{BAHAN DAN METODE PENELITIAN}

Pada penelitian ini digunakan desain penelitian kuantitatif dengan pendekatan cross sectional, untuk mengetahui hubungan kualitas pelayanan kesehatan terhadap kepuasan pasien pengguna badan penyelenggara jaminan sosial di Puskesmas Maiwa Kabupaten Enrekang. Alat ukur penelitian yang digunakan adalah kuesioner, dimana data diperoleh dari pasien dengan mengajukan pertanyaan-pertanyaan yang berkaitan dengan variabel yang diteliti. Populasi dalam penelitian ini adalah seluruh pasien pengguna BPJS yang berkunjung ke Puskesmas pada tahun 2017 adalah 2.072 orang. Teknik pengambilan sampel dilakukan secara Accidental sampling yaitu teknik penentuan sampel berdasarkan kebetulan, yaitu siapa saja yang secara kebetulan/ Accidental bertemu dengan penelitian dapat digunakan sebagai sampel, bila dipandang orang yang kebetulan ditemukan cocok sebagai sumber data, untuk mendapatkan data yang sesuai dengan fokus penelitian. Data yang kumpulkan menggunakan bantuan kuesioner diolah secara komputerisasi SPSS untuk menentukan frekuensi dan disajikan dalam bentuk tabel analisis univariat. Analisis univariat bertujuan untuk menjelaskan atau mendeskripsikan karasteristik setiap pariabel penelitian. Bentuk analisis univariat tergantung jenis dan datanya tetapi pada umumnya dalam analisis ini hanya menghasilkan distribusi frekuensi dan persentase dari tiap variabel. ${ }^{11}$

Analisis Bivariat digunakan untuk melihat hubungan antara variabel dependen yaitu Kepuasan pengguna BPJS variabel independen.Pada analisis ini digunakan Chi Square yang digunakan untuk menguji hipotesis hubungan kualitas pelayanan kesehatan terhadap kepuasan pasien BPJS. Dasar pengambilan keputusan penerimaan hipotesis penelitian berdasarkan tingkap signifikan (nila $p$ ), jika nilai $p>0,05$ maka hipotesis penelitian ditolak dan jika $p<0,05$ maka hipotesis diterima. ${ }^{12}$ Analisis multifariat adalah salah satu dari teknik statistik yang digunakan untuk memahami struktur data dalam dimensi tinggi.Dimana variabel-variabel yang di maksut tersebut saling terkait satu sama lain. ${ }^{13}$

\section{HASIL PENELITIAN}

Distribusi responden berdasarkan umur pada tabel 1 menunjukkan bahwa umur 5-30 tahun sebanyak 32 responden (33,7\%), umur 31-45 tahun sebanyak 17 responden (17,9\%), umur $\geq 46$ tahun sebanyak 46 responden $(48,4 \%)$. Dari data diperoleh umur responden yang terbanyak datang berkunjung di Puskesmas dengan menggunakan BPJS yaitu umur $\geq 46$ tahun sebanyak 46 responden $(48,4 \%)$ umur yang lebih tua dikarenakan pada saat pengambilan data di lokasi penelitian ratarata yang datang berkunjung dengan menggunakan BPJS adalah $\geq 46$ dengan alasan 
berobat ke Puskesmas lebih mudah dan dekat. Selanjutnya diperoleh distribusi responden berdasarkan jenis kelamin yaitu laki-laki sebanyak 42 responden $(44,2 \%)$, dan perempuan sebanyak 53 responden $(55,8 \%)$. Dari data diperoleh jenis kelamin yang dominan yaitu pasien yang paling banyak berkunjung di Puskesmas Maiwa dengan menggunakan BPJS yaitu perempuan sebanyak 53 responden $(55,8 \%)$ dibandingkan laki-laki. Sedangkan distribusi responden berdasarkan pekerjaan yaitu petani sebanyak 19 responden (20,0\%), IRT sebanyak 26 responden $(27,4 \%)$, pelajar sebanyak 26 responden $(27,4 \%)$, wiraswasta sebanyak 22 responden (24,2\%), PNS/TNI/POLRI sebanyak 1 responden $(1,1 \%)$. Dari data diperoleh pekerjaan responden yang paling banyak datang berkunjung di Puskesmas Maiwa dengan menggunakan BPJS yaitu IRT sebanyak 26 responden dan pelajar dengan 26 responden $(27,4 \%)$ dan yang paling sedikit yaitu PNS/TNI/POLRI sebayak 1 responden $(1,1 \%)$.

Distribusi jawaban responden mengenai hubungan bukti fisik dengan kepuasan pasien pada Tabel 2 menunjukkan bahwa responden yang menjawab baik dengan kepuasan pasien baik sebanyak 66 orang $89,2 \%$, yang menjawab tidak baik dengan kepuasan pasien baik sebanyak 11 orang 47,6\% dan yang menjawab dimensi bukti fisik baik dengan kepuasan pasien tidak baik sebanyak 8 orang $10,8 \%$, yang menjawab tidak baik dengan kepuasan pasien tidak baik sebanyak 10 orang
47,6\%. Berdasarkan hasil uji chi-square maka diperoleh nilai $p=0,001$.

Jawaban responden mengenai hubungan kehandalan dengan kepuasan pasien pada Tabel 3 menunjukkan bahwa responden yang menjawab baik dengan kepuasan pasien baik sebanyak 56 orang $82,4 \%$, yang menjawab tidak baik dengan kepuasan pasien baik sebanyak 21 orang $77,8 \%$ dan yang menjawab dimensi kehandalan baik dengan kepuasan pasien tidak baik sebanyak 12 orang $17,6 \%$, yang menjawab tidak baik dengan kepuasan pasien tidak baik sebanyak 6 orang 22,2\%. Berdasarkan hasil uji chi-square maka diperoleh nilai $p=0,402$. Untuk jawaban responden mengenai hubungan tanggapan dengan kepuasan pasien pada Tabel 4 menunjukkan bahwa responden yang menjawab baik dengan kepuasan pasien baik sebanyak 66 orang 86,8\%, yang menjawab tidak baik dengan kepuasan pasien baik sebanyak 11 orang $57,9 \%$ dan yang menjawab dimensi daya tanggap baik dengan kepuasan pasien tidak baik sebanyak 10 orang 13,2\%, yang menjawab tidak baik dengan kepuasan pasien tidak baik sebanyak 8 orang $42,1 \%$. Berdasarkan hasil uji chi-square maka diperoleh nilai $p=0,008$.

Jawaban responden mengenai hubungan jaminan dengan kepuasan pasien pada Tabel 5 menunjukkan bahwa responden yang menjawab baik dengan kepuasan pasien baik sebanyak 72 orang $87,8 \%$, yang menjawab tidak baik dengan kepuasan pasien baik sebanyak 5 orang $38,5 \%$ dan yang 
menjawab dimensi jaminan baik dengan kepuasan pasien tidak baik sebanyak 10 orang $12,2 \%$, yang menjawab tidak baik dengan kepuasan pasien tidak baik sebanyak 8 orang 61,5\%. Berdasarkan hasil uji chi-square maka diperoleh nilai $p=0,000$. Sedangkan distribusi jawaban responden mengenai hubungan emphaty dengan kepuasan pasien pada Tabel 6 menunjukkan bahwa responden yang menjawab baik dengan kepuasan pasien baik sebanyak 69 orang 86,3\%, yang menjawab tidak baik dengan kepuasan pasien baik sebanyak 8 orang $53,3 \%$ dan yang menjawab dimensi bukti fisik baik dengan kepuasan pasien tidak baik sebanyak 11 orang $13,8 \%$, yang menjawab tidak baik dengan kepuasan pasien tidak baik sebanyak 7 orang $46,7 \%$. Berdasarkan hasil chi-square maka diperoleh nilai $p=0,007$.

Distribusi data regresi antara variabel bukti fisik, tanggapan, jaminan, dan emphaty terhadap kepuasan pasien di Puskesmas Maiwa Tabel 7 menunjukkan bahwa dari hasil penelitian dimensi jaminan dengan tingkat signifikan nilai $p=0,017$, bukti fisik dengan meliputi tingkat signifikan diperoleh nilai $p=0,066$, tanggapan dengan meliputi tingkat signifikan diperoleh nilai $p=0,419$, empaty dengan meliputi tingkat signifikan diperoleh nilai $p=0,388$. Berdasarkan 4 dimensi yang paling berhubungan dengan kualitas pelayanan dengan kepuasan pasien pengguna BPJS adalah dimensi jaminan dengan tingkat signifikan nilai $p=0,017$.

\section{PEMBAHASAN}

Hasil penelitian menunjukkan bahwa sebagian besar responden yang periksa dengan menggunakan kartu BPJS di Puskesmas Maiwa adalah berumur sebanyak 46 responden $(48,4 \%)$, sementara sebagian kecil berumur 31-45 tahun sebanyak 17 responden $(17,9 \%)$, hal tersebut berdasarkan wawancara dengan responden usia yang tebih tua lebih memilih berobat ke puskesmas karena lebih mudah dan dekat dari rumah mereka, serta pada umur $\geq 46$ tahun rentang terkena penyakit.

Berdasarkan hasil penyebaran kuesioner penelitian yang disebarkan pada 95 responden dengan jumlah laki-laki sebanyak 42 orang dan jumlah perempuan sebanyak 53 orang. Data tersebut didapatkan responden perempuan lebih banyak dibandingkan responden laki-laki dengan persentase 55,8\% jenis kelamin perempuan dan $44,2 \%$ jenis kelamin laki-laki.

Berdasarkan data pasien di Puskesmas Maiwa pada periode Januari-Desember tahun 2017 sebanyak 807 untuk laki-laki dan 1.265 untuk perempuan. Proporsi perempuan lebih banyak dibandingkan dengan laki-laki yaitu perempuan berjumlah 11,809 jiwa dan laki-laki berjumlah 11.793 jiwa.

Hasil penelitian menunjukkan bahwa responden yang berjenis kelamin perempuan lebih besar sekitar 51,3\%. Hasil penelitian tersebut menyatakan bahwa jenis kelamin tidak mempunyai pengaruh yang berarti terhadap sudut pandang pasien akan kualitas pelayanan yang diberikan. ${ }^{6}$ 
Berdasarkan dari hasil dimensi bukti fisik kualitas pelayanan kesehatan yang menjawab baik sebanyak $(89,2 \%)$, dan yang menyatakan tidak baik sebanyak $(47,6 \%)$. Hal yang mendukung (Tangibles) pelayanan yang mengatakan baik adalah kemampuan petugas puskesmas dalam melayani pasien dianggap sudah baik dengan memiliki papan petunjuk yang jelas, mudah ditemukan dalam memeberikan arahan kepada pasien dan penampilan dokter/perawat sudah bersih dan rapih, yang menyatakan tidak baik adalah alatalat medis belum lengkap dengan ruangan yang belum tertata rapih.

Hasil dari dimensi tanggapan kualitas pelayanan kesehatan yang menjawab baik sebanyak $(80,0 \%)$. yang menyatakan tidak baik sebanyak (20,0\%). Hal yang mendukung (Responsivenes) kualitas pelayanan yang sudah baik adalah tenaga medis selalu memberi penjelasan tentang aturan minum obat, kemudahan mendapat informasi. Kemudian dokter selalu memberi penjelasan tentang penyakit yang diderita, dokter selalu menanyakan keluhan pasien, dan pegawai bersikap sopan. Masih ada juga responden yang merasa tidak puas dengan pelayanan (Responsivenes) yang diberikan dengan alasan masih ada petugas yang terkadang tidak peduli dan acuh saat datang ke puskesmas.

$$
\text { Hasil penelitian empati dalam }
$$
pelayanan kesehatan yang menjawab baik sebanyak $(84,2 \%)$, dan yang menjawab tidak baik sebanyak (13,7\%). Hal yang mendukung (emphaty) yang sudah baik adalah kesediaan dokter menenangkan rasa cemas pasien terhadap penyakit yang diderita. Perlakuan yang diberikan kepada pasien semata-mata untuk kesembuhan responden dengan peduli akan keinginan pasien. Sedangkan yang mengatakan tidak puas adalah kesediaan petugas meminta maaf bila terjadi kesalahan dan penyediaan tenaga medis yang di anggap belum tanggap dalam melayani pasien.

Hasil penelitian Kepuasan yang menjawab baik sebanyak $(81,1 \%)$, dan yang menyatakan tidak baik sebanyak $(18,1 \%)$. Hal yang mendukung kepuasan yang sudah baik adalah penerangan ruang periksa pasien sudah cukup dengan ruang tunggu di puskesmas sudah nyaman dan bersih. Kemudian selalu memahami keinginan pasien pengguna (BPJS), dan mengalami kesembuhan setelah pasien menerimah tindakan dari perawat. Sedangkan yang mengatakan tidak baik adalah responden pengguna (BPJS) yang masih mengeluhkan prosedur pendaftaran pasien yang belum dilayani secara cepat, tepat, dan cenderung berbelit-belit.

Berdasarkan dimensi jaminan kualitas pelayanan kesehatan berada mencapai tingkat tertinggi yaitu sebesar $(86,3 \%)$ yang mengatakan baik. Sedangkan yang mengatakan tidak baik sebesar $(13,7 \%)$. Hal tersebut disebabkan karena petugas puskesmas selalu memberikan jaminan kesembuhan dengan bersikap sopan dan berusaha memperlakukan responden pengguna (BPJS) senyaman mungkin saat datang berkunjung. 
Sedangkan dimensi kehandalan mencapai tingkat terendah yaitu sabesar $(71,6 \%)$ yang menyatakan baik, dan yang mengatakan tidak baik sebesar $(28,4 \%)$. Hal tersebut disebabkan karena responden pengguna (BPJS) menyatakan bahwa tidak adanya petugas yang memberikan arahan saat pertama datang berkunjung di puskesmas. Masyarakat pengguna (BPJS) juga mengatakan bahwa terkadang obat yang diberikan petugas tidak mempan saat di minum. Pada saat konsultasi dengan dokter terkadang mereka tidak mngerti akan penjelasan dari dokter

Analisis Bivariat digunakan untuk melihat hubungan antara variabel dependen yaitu Kepuasan pengguna BPJS variabel independen. $^{7}$

Hasil penelitian Tabel 2 menunjukkan bahwa responden yang berdasarkan dimensi empati menunjukkan bahwa responden yang menjawab baik dengan kepuasan pasien baik sebanyak 69 orang 86,3\%. Sedangkan yang menjawab tidak baik dengan kepuasan pasien baik sebanyak 8 orang 53,3\%. Yang menjawab dimensi bukti fisik baik dengan kepuasan pasien tidak baik sebanyak 11 orang $13,8 \%$, yang menjawab tidak baik dengan kepuasan pasien tidak baik sebanyak 7 orang $46,7 \%$.

Hal yang mendukung bukti fisik pelayanan yang sudah baik adalah petugas puskesmas dalam memberikan pelayanan serta papan petunjuk yang mudah dan jelas. Begitupun dalam memberikan arahan dan penampilan dokter/perawat sudah bersih dan rapih, sebagian kecil responden yang masih mengharap bukti fisik pelayanan yang lebih baik. Mereka masih mengeluhkan alat-alat medis yang belum lengkap serta ruang rawat inap yang belum tertata rapih. Hal ini masih perlu mendapatkan perhatian khusus dari pihak puskesmas itu sendiri.

Hasil penelitian ini sejalan dengan penelitian yang dilakukan oleh Siswati (2015) yang menyatakan bahwa ada hubungan antara tangible dengan kepuasan pasien BPJS di unit rawat inap RSUD Kota Makassar. Bukti fisik (Tangible) oleh pasien dikatakan baik dan puas dengan kualitas pelayanan yang dirasakan karena pasien merasa fasilitas yang disediakan di RSUD Kota Makassar sudah baik terhadap petugas rumah sakit (clening service) yang menjaga kebersihan rumah sakit. Pasien yang menyatakan tangible baik tetapi tidak merasa puas disebabakan oleh persepsi pasien yang merasakan tidak baik terhadap kebersihan kamar mandi, dan juga ruangan perawatan. Selain itu, air di kamar mandi yang kadang tidak mengalir dengan baik serta peralatan elektronik yang terdapat diruangan perawatan pasien tidak berfungsi dengan baik. Seperti yang ada dalam kamar mandi tetapi tidak mendapatkan perbaikan dan beberapa ruangan memiliki pendingin yang tidak berfungsi dengan baik, sehingga pasien dan keluarga yang menjaga merasa kepanasan di dalam ruangan. Hal ini sesuai dengan hasil uji statistik dengan menggunakan fisher's exact text diperoleh nilai $p=0,000{ }^{8}$

Hasil penelitian dimensi kehandalan pada Tabel 3 menunjukkan bahwa responden 
yang menjawab baik dengan kepuasan pasien baik sebanyak 56 orang $82,4 \%$, yang menjawab tidak baik dengan kepuasan pasien baik sebanyak 21 orang 77,8\%. Sedangkan yang menjawab dimensi kehandalan baik dengan kepuasan pasien tidak baik sebanyak 12 orang $17,6 \%$. Yang menjawab tidak baik dengan kepuasan pasien tidak baik sebanyak 6 orang $22,2 \%$, sesuai dengan hasil uji chisquare diperoleh nilai $p=0,402$. Hal tersebut menunjukkan bahwa tidak ada hubungan kehandalan dengan kualitas pelayanan kesehatan terhadap kepuasan pasien pengguna BPJS di Puskesmas Maiwa.

Hal ini disebabkan karena masih adanya responden yang tidak mendengarkan sungguhsungguh keluhan tentang penyakit yang pasien derita. Jarang memberikan jalan keluar dalam berobat, responden juga mengeluhkan dokter yang terkadang tidak datang tepat waktu dan pasien yang datang berkunjung dengan menggunakan kartu BPJS.

Berbeda dengan hasil penelitian yang dilakukan oleh Yuristi (2013) menunjukkan beberapa responden memiliki persepsi bahwa kehandalan perawat yang baik adalah jika perawat mampu memberikan pelayanan pemeriksaan dengan cepat atau mereka menilai kualitas dari segi waktu (faster) artinya bahwa pasien memiliki persepsi bahwa jika perawat mampu memeriksa pasien dengan segera maka bagi mereka itulah pelayanan yang berkualitas. Selain itu pada saat mereka pertama kali di rawat inap perawat menerima mereka tanpa prosedur yang berbelit-belit. ${ }^{9}$
Hasil penelitian dimensi tanggap pada Tabel 4 menunjukkan bahwa responden yang menjawab baik dengan kepuasan pasien baik sebanyak 66 orang 86,8\%, yang menjawab tidak baik dengan kepuasan pasien baik sebanyak 11 orang $57,9 \%$ dan yang menjawab dimensi daya tanggap baik dengan kepuasan pasien tidak baik sebanyak 10 orang $13,2 \%$, yang menjawab tidak baik dengan kepuasan pasien tidak baik sebanyak 8 orang $42,1 \%$. Berdasarkan hasil uji chi-square maka diperoleh nilai $p=0,008$. Beberapa hal yang mendukung daya tanggap kualitas pelayanan yang sudah baik adalah cara tenaga medis menjelaskan jenis penyakit dengan cara minum obat secara teratur, kemudahan mendapatkan kejelasan informasi pelayanan kesehatan, penjelasan tentang penyakit yang diderita, menanyakan keluhan pasien, dan pegawai bersikap sopan dan ramah.

Sebagian kecil masih ada responden yang masih mengharap daya tanggap untuk lebih baik lagi seperti keramahan petugas kepada responden masih perlu ditingkatkan lagi agar responden merasa nyaman saat datang berkunjung. Berdasarkan hasil uji chisquare diperoleh nilai $p=0,008$. Hal tersebut menunjukkan bahwa ada hubungan daya tanggap dengan kualitas pelayanan kesehatan terhadap kepuasan pasien pengguna BPJS di Puskesmas Maiwa. Hal ini dibuktikan setelah dilakukan survei dimna perilaku dokter ketika melayani mereka apakah baik tau tidak dan mereka mengatakan pelayanan yang diberikan dari dokter baik. 
Hasil penelitian ini sejalan dengan penelitian yang dilakukan Yuristi (2013) yang menyatakan mereka rasakan perawat mampu mendengarkan keluhan dari pasien, memberikan informasi yang jelas tentang keadaan penyakit mereka dan pelayanan yang ada dirumah sakit. Hal ini menunjukkan bahwa perawat besungguh-sungguh dan bersedia memberi pertolongan kepada pasien yang membutuhkan. Berdasarkan hasil penelitian menunjukkan bahwa kepuasan pasien terhadap daya tanggap pelayanan mempunyai hubungan terhadap kepuasan pasien pengguna akses sosial pada pelayanan rawat inap dengan (p value $=0,027){ }^{9}$

Berdasarkan hasil penelitian dimensi jaminan pada Tabel 5 menunjukkan bahwa responden yang menjawab baik dengan kepuasan pasien baik sebanyak 72 orang $87,8 \%$, yang menjawab tidak baik dengan kepuasan pasien baik sebanyak 5 orang 38,5\%. Dimensi jaminan yang menjawab baik dengan kepuasan pasien tidak baik sebanyak 10 orang $12,2 \%$, yang menjawab tidak baik dengan kepuasan pasien tidak baik sebanyak 8 orang $61,5 \%$. Berdasarkan hasil uji chi-square maka diperoleh nilai $p=0,000$.

Hal yang mendukung assurance pelayanan yang sudah baik adalah dokter yang memberi rasa aman, kesopanan petugas puskesmas dalam memperlakukan responden saat datang berkunjung, keamanan yang terjaga saat antri maupun kegiatan pengobatan dan mampu melayani responden pada saat datang berkunjung. Adapun sebagian kecil yang mengharap assurance pelayanan yang lebih baik dengan mengharapkan agar dokter lebih meyakinkan responden jaminan atas kesembuhan responden, sesuai dengan hasil uji chis-quare diperoleh nilai $p=0,000$. Hal ini menunjukkan bahwa ada hubungan jaminan dengan kualitas pelayanan kesehatan terhadap kepuasan pasien pengguna BPJS di Puskesmas Maiwa. Hal ini dibuktikan setelah dilakukan survei langsung dimna cara petugas memberikan harapan kepasien dengan memberikan jaminan kesembuhan pada pasien mereka memang sangat berusaha agar pasien yang datang ke Puskesmas agar merasa puas akan pelayanan yang diberikan ketika datng berkunjung.

Hasil penelitian ini sejalan dengan penelitian yang dilakukan oleh Yuristi (2013) menunjukkan bahwa beberapa responden yang menunjukkan bahwa sebagian jaminan pelayanan (assurance) di RSUD Lakipadada sudah baik karena sebagian besar responden menyatakan baik selama menggunakan fasilitas pelayanan rawat inap di RS Lakipadada. Sebagian kecil responden yang masih mengharapkan jaminan pelayanan yang lebih baik. Mereka masih mengeluhkan pengetahuan petugas dalam menangani masalah/ keluhan mereka. Hal ini perlu mendapat perhatian khusus dari pihak rumah sakit dengan cara meningkatkan SDM semua perawat baik kualitas maupun kuantitas melalui penambahan tenaga sesuai kebutuhan. Hal ini menunjukkan jaminan pelayanan (assurance) di RSUD Lakipadada mempunyai 
hubungan terhadap kepuasan pasien pengguna akses sosial pada pelayanan rumah sakit rawat inap dengan $(p$ volue $=0,027){ }^{9}$

Hasil penelitian berdasarkan dimensi empati pada Tabel 6 menunjukkan bahwa responden yang menjawab baik dengan kepuasan pasien baik sebanyak 69 orang $86,3 \%$, yang menjawab tidak baik dengan kepuasan pasien baik sebanyak 8 orang 53,3\%. Sedangkan yang menjawab dimensi bukti fisik baik dengan kepuasan pasien tidak baik sebanyak 11 orang $13,8 \%$, yang menjawab tidak baik dengan kepuasan pasien tidak baik sebanyak 7 orang $46,7 \%$. Berdasarkan hasil chi-square maka diperoleh nilai $p=0,007$.

Hal yang mendukung (emphaty) pelayanan yang sudah baik adalah penerapan ruangan pasien sudah cukup, ruang tunggu puskesmas sangat nyaman dan bersih, selalu memahami keinginan pasien, kesembuhan setelah meminum pasien minum obat, sebagian kecil masih ada responden yang mengharap emphaty pelayanan yang lebih baik dengan mengeluhkan prosedur pendaftaran responden dilayani secara tepat, cepat, dan tidak berbelitbelit. Hal ini masih perlu mendapatkan perhatian khusus dari pihak puskesmas agar lebih memperhatikan keinginan responden. Hasil penelitian menunjukkan bahwa ada hubungan emphaty dengan kualitas pelayanan kesehatan terhadap kepuasan pasien pengguna BPJS di Puskesmas Maiwa. Sesuai dengan hasil uji chis-quare diperoleh nilai $p=0,007$. Karena pada saat melakukan penelitian petugas berusaha menyediakan tenaga medis bagi pengguna BPJS agar mereka tidak merasa kekurangan.

Hasil penelitian ini juga sejalan dengan penelitian yang dilakukan oleh Saputro (2015) yang menyatakan bahwa dimensi emphaty di RS Bethesda Yogyakarta diwakili oleh empat pernyataan yaitu jam buka pelayanan, komunikasi petugas dengan pasien, petugas mengetahui apa yang dibutuhkan pasien dan petugas melayani dengan tulus. Maka diketahui dari 112 pasien rawat jalan tanggungan BPJS menyatakan bahwa dimensi emphaty pada tingkat kualitas pelayanan. Sedangkan keempat pernyataan yang mewakili variabel dimensi emphaty diperoleh skor ratarata $68,39 \%$ pada kategori cukup, ini menunjukan bahwa dari 112 responden menyatakan dimensi emphaty yang merupakan syarat untuk peduli, memberi perhatian pribadi bagi pasien masih dinilai cukup. Hal ini berarti bahwa ada hubungan antara emphaty dengan kepuasan pasien BPJS di RS Bethesda Yogyakarta ${ }^{10}$.

Analisis multivariat adalah salah satu dari teknik statistik yang diterapkan untuk memahami struktur data dalam dimensi tinggi. Dimana variabel-variabel yang dimaksud tersebut saling terkait satu sama lain. ${ }^{7}$ Berdasarkan dimensi bukti fisik, tanggapan, jaminan, emphaty yang paling berhubungan yaitu dimensi jaminan dengan nilai signifikan $p=0,017$. Hasil tersebut dikatakan paling berhubungan karena masyarakat yang menggunakan BPJS mengatakan bahwa pada saat pasien berkonsultasi dengan dokter merasa 
nyaman dengan mengatakan menjamin akan kesembuhan pasien dengan mengikuti saran dari dokter. Pasien juga menyatakan bahwa kesopanan petugas Puskesmas dalam memperlakukan pasien saat datang berkunjung rata-rata mengatakan baik dan keamanan pada saat antri pasien merasa aman dan nyaman.

\section{KESIMPULAN DAN SARAN}

Hasil penelitian yang dilakukan di Puskesmas Maiwa Kabupaten Enrekang pada tanggal 10 Maret sampai 07 Juli 2018 memberi kesimpulan bahwa ada hubungan bukti fisik (tangible) kualitas pelayanan kesehatan, tanggapan (responsiveness) pelayanan kesehatan, dan perhatian (emphaty) pelayanan kesehatan dengan kepuasan pasien pengguna BPJS di Puskesmas Maiwa serta tidak ada hubungan kehandalan (reliability) pelayanan kesehatan dengan kepuasan pasien pengguna BPJS di Puskesmas Maiwa. Berdasarkan hasil penelitian yang dilakukan mengenai hubungan kualitas pelayanan kesehatan dengan kepuasan pasien pengguna BPJS di Puskesmas Maiwa Kabupaten Enrekang maka saran yang dapat disampaikan peneliti adalah pihak Puskesmas dapat mempertahankan bukti fisik (tangible) pelayanan kesehatan dengan kepuasan pasien

\section{DAFTAR PUSTAKA}

1. Steven K. 2014. Pelayanan Kesehatan Masyarakat di Puskesmas Desa Gunawah Kecamatan Sesayap Kabupaten Tana Tidung.Jurnal Ilmu Pemerintahan, Vol 2, No 1. [Diakses tanggal 14 Maret 2018] pengguna BPJS di Puskesmas Maiwa. Berdasarkan kemampuan petugas puskesmas dalam melayani pasien dan berpenampilan bersih dan rapih bagi petugas yang bertugas, mempertahankan tanggapan (responsiveness) dengan cara medis menjelaskan tentang penyakit pasien dan minum obat secara teratur, kemudahan mendapatkan kejelasan informasi pelayanan kesehatan, mempertahankan jaminan (assurance) dengan cara memberikan rasa aman kepada pasien dan kesopanan patugas dalam memperlakukan pasien saat datang berkunjung, dan mempertahankan perhatian (emphaty) dengan penerangan ruangan yang cukup dan memahami keinginan pasien. Selain itu, diharapkan pada peneliti selanjutnya agar melakukan penelitian yang berkaitan dengan hubungan kehandalan (reliability) pelayanan kesehatan dengan kepuasan pasien pengguna BPJS di Puskesmas Maiwa. meningkatkan pelayanan dengan meningkatkan kualitas pelayanan seperti memberikan informasi yang jelas sebelum melakukan pelayanan, mendengarkan sungguh-sungguh keluhan pasien tentang penyakitnya yang diderita, kesiapan dan ketepatan waktu dokter ketika berugas.

2. Sulistyo BP. 2016. Hubungan Kualitas Pelayanan kesehatan Dengan Tingkat Kepuasan Pasien BPJS Di Puskesmas Delanggu Kabupaten Klaten. [Skripsi] : Keperawatan Stikes Kusuma Hudasa Surakarta 
3. Ningrum A. 2015. Respon Kepuasan Pasien Pengguna BPJS Kesehatan Terhadap Pelayanan Kesehatan di Puskesmas Pekanbaru Vol.2 No.2. FISIP Universitas Riau.

4. Bahtiar R. 2014. Studi tingkat Kepuasan Masyarakat Pengguna Kartu BPJS Terhadap Pelayanan Kesehatan Di Puskesmas Mangasa Kota Makassar : Jurnal. [Diakses 14 Juli 2018]

5. Defa S. 2017. Kepuasan Terhadap Kualitas Pelayanan BPJS Kesehatan (Studi kasus di Rumha Sakit Abdul Moeloek Provinsi Lampung). [Sripsi] : Universitas Lampung Bandar Lampung.

6. Yuniarti S. 2015. Hubungan antara Kualitas Pelayanan Rumah Sakit dengan Tingkat Kepuasan Pasien BPJS Di Ruang Rawat RSUD Sultan Syarif Mohammad Alkadrie Kota Pontianak Tahun 2015. [Skripsi]. Program Studi Keperawatan Fakultas Kedokteran Universitas Tanjungpura Pontianak.

7. Notoadmodjo, S. 2012. Metodologi Penelitian Kesehatan.Rineca Cipta:Jakarta..

8. Siswati S. 2015. Kualitas Pelayanan Kesehatan dengan Kepuasan Pasien BPJS Unit Rawat Inap RSUD Kota Makassar Tahun

9. Yuristi BW. 2013. Hubungan Kualitas Pelayanan Kesehatan dengan Kepuasan
Pasien Penggunga Akses Sosial pada Pelayanan Rawat Inap Di RSUD Lakipadada Kabupaten Tana Toraja Tahun 2013. [Skripsi]. Bagian Administrasi Dan Kebijakan Kesehatan Fakultas Kesehatan Masyarakat Universitas Hasanuddin

10. Saputro DA. 2015. Hubungan Kualitas Pelayanan Kesehatan dengan Kepuasan Pasien Rawat Jalan Tanggungan BPJS Di Rumah Sakit Bethesda Yogyakarta. [Skripsi]. Program Studi Kesehatan Masyarakat Fakultas Ilmu Kesehatan Universitas Muhammadiyah Surakarta.

11. Martina. 2011. Pengaruh Kualitas Pelayanan Kesehatan Terhadap Kepuasan Pasien Rawat Inap RSUD Cut Meutia Kabupaten Aceh Utara. Fakultas Ilmu Sosial dan Ilmu Politik. [Skripsi]. Universitas Universitas Sumatra Utara.

12. Puji PI. 2016. Hubungan Kepuasan Pasien Pengguna BPJS terhadap Kualitas Pelayanan Keseahatan Di Puskesmas Nagrak Sukabumi. [Skripsi] Universitas Islam Negeri Syarif Hidayatullah.

13. Nurani T. 2012. Pengaruh Kualitas Pelayanan Kesehatan Terhadap Kepuasan Pengguna Jasa Rawat Inap di RSUD

Dr.

Moewardi.[Skripsi].Universitas

Muhammadiyah Surakarta. 


\section{LAMPIRAN}

Tabel 1. Karakteristik Responden Berdasarkan Umur, Jenis Kelamin, dan Pekerjaan Pasien Pengguna BPJS Mandiri diPuskesmas Maiwa Kabupaten Enrekang

\begin{tabular}{ccc}
\hline Karakteristik & n & \% \\
\hline Umur (Tahun) & 32 & 33,7 \\
$5-30$ & 17 & 17,9 \\
$31-45$ & 46 & 48,4 \\
$\geq 46$ & 95 & 100,0 \\
\hline Total & & \\
Jenis Kelamin & 42 & 44,2 \\
Laki-laki & 53 & 55,8 \\
Perempuan & 95 & 100,0 \\
Total & & \\
Pekerjaan & 19 & 20,0 \\
Petani & 26 & 27,4 \\
IRT & 26 & 27,4 \\
Pelajar & 23 & 24,2 \\
Wiraswasta & 1 & 1,1 \\
PNS/TNI/POLRI & 95 & 100,0 \\
\hline Total & &
\end{tabular}

Tabel 2. Data Kepuasan Pasien Pengguna BPJS di Puskesmas Maiwa Kabupaten Enrekang.

\begin{tabular}{ccc}
\hline Bukti fisik & Frequency & \% \\
\hline Baik & 74 & 77,9 \\
Tidak baik & 21 & 22,1 \\
Total & 95 & 100,0 \\
Kehandalan & & \\
Baik & 68 & 71,6 \\
Tidak Baik & 27 & 28,4 \\
Total & 95 & 100,0 \\
Tanggapan & & \\
Baik & 76 & 80,0 \\
Tidak Baik & 19 & 20,0 \\
Total & 95 & 100,0 \\
Jaminan & Frequency & $\mathbf{\%}$ \\
Baik & 82 & 86,3 \\
Tidak baik & 13 & 13,7 \\
Total & 95 & 100,0 \\
Emphaty & Frequency & $\mathbf{\%}$ \\
Baik & 80 & 84,2 \\
Tidak baik & 15 & 15,8 \\
Total & 95 & 100,0 \\
Kepuasan & Frequency & $\mathbf{\%}$ \\
Baik & 77 & 81,1 \\
Tidak baik & 18 & 18,9 \\
Total & 95 & 100,0 \\
\hline
\end{tabular}


Tabel 2. Hubungan Bukti Fisik dengan Kepuasan Pasien di PuskesmasMaiwa Kabupaten Enrekang.

\begin{tabular}{|c|c|c|c|c|c|c|c|}
\hline \multirow{3}{*}{ Bukti fisik } & \multicolumn{4}{|c|}{ Kepusan pasien } & \multicolumn{2}{|c|}{ Total } & \multirow{3}{*}{$p$} \\
\hline & \multicolumn{2}{|c|}{ Baik } & \multicolumn{2}{|c|}{ Tidak baik } & \multirow[b]{2}{*}{$\mathrm{n}$} & \multirow[b]{2}{*}{$\%$} & \\
\hline & $\mathrm{n}$ & $\%$ & $\mathrm{n}$ & $\%$ & & & \\
\hline Baik & 66 & 89,2 & 8 & 10,8 & 74 & 100,0 & \multirow{3}{*}{0,001} \\
\hline Tidak Baik & 11 & 52,4 & 10 & 47,6 & 21 & 100,0 & \\
\hline Total & 77 & 81,1 & 18 & 18,9 & 95 & 100,00 & \\
\hline
\end{tabular}

Tabel 3. Hubungan Kehandalan dengan Kepuasan Pasien di Puskesmas Maiwa Kabupaten Enrekang.

\begin{tabular}{|c|c|c|c|c|c|c|c|}
\hline \multirow{3}{*}{ Kehandalan } & \multicolumn{4}{|c|}{ Kepusan pasien } & \multicolumn{2}{|c|}{ Total } & \multirow{3}{*}{$P$} \\
\hline & \multicolumn{2}{|c|}{ Baik } & \multicolumn{2}{|c|}{ Tidak baik } & \multirow[b]{2}{*}{$\mathrm{n}$} & \multirow[b]{2}{*}{$\%$} & \\
\hline & $\mathrm{n}$ & $\%$ & $\mathrm{n}$ & $\%$ & & & \\
\hline Baik & 56 & 82,4 & 12 & 17,6 & 68 & 100,0 & \multirow{3}{*}{0,402} \\
\hline Tidak Baik & 21 & 77,8 & 6 & 22,2 & 27 & 100,0 & \\
\hline Total & 77 & 81,1 & 18 & 18,9 & 95 & 100,00 & \\
\hline
\end{tabular}

Tabel 4. Hubungan Tanggapan dengan Kepuasan Pasien di Puskesmas Maiwa Kabupaten Enrekang.

\begin{tabular}{|c|c|c|c|c|c|c|c|}
\hline \multirow{3}{*}{ Tanggapan } & \multicolumn{4}{|c|}{ Kepusan pasien } & \multicolumn{2}{|c|}{ Total } & \multirow{3}{*}{$p$} \\
\hline & \multicolumn{2}{|c|}{ Baik } & \multicolumn{2}{|c|}{ Tidak baik } & \multirow[b]{2}{*}{$\mathrm{n}$} & \multirow[b]{2}{*}{$\%$} & \\
\hline & $\mathrm{n}$ & $\%$ & $\mathrm{n}$ & $\%$ & & & \\
\hline Baik & 66 & 86,8 & 10 & 13,2 & 76 & 100,0 & \\
\hline Tidak Baik & 11 & 57,9 & 8 & 42,1 & 19 & 100,0 & 0,008 \\
\hline Total & 77 & 81,1 & 18 & 18,9 & 95 & 100,00 & \\
\hline
\end{tabular}

Tabel 5. Hubungan Jaminan dengan Kepuasan Pasien di Puskesmas Maiwa Kabupaten Enrekang

\begin{tabular}{|c|c|c|c|c|c|c|c|}
\hline \multirow{3}{*}{ Jaminan } & \multicolumn{4}{|c|}{ Kepusan pasien } & \multicolumn{2}{|c|}{ Total } & \multirow{3}{*}{$p$} \\
\hline & \multicolumn{2}{|c|}{ Baik } & \multicolumn{2}{|c|}{ Tidak baik } & \multirow[b]{2}{*}{$\mathrm{n}$} & \multirow[b]{2}{*}{$\%$} & \\
\hline & $\mathrm{n}$ & $\%$ & $\mathrm{~N}$ & $\%$ & & & \\
\hline Baik & 72 & 87,8 & 10 & 12,2 & 82 & 100,0 & \\
\hline Tidak Baik & 5 & 38,5 & 8 & 61,5 & 13 & 100,0 & 0,000 \\
\hline Total & 77 & 81,1 & 18 & 18,9 & 95 & 100,00 & \\
\hline
\end{tabular}

Tabel 6. Hubungan Emphaty dengan Kepuasan Pasien di Puskesmas Maiwa Kabupaten Enrekang.

\begin{tabular}{|c|c|c|c|c|c|c|c|}
\hline \multirow{3}{*}{ Empati } & \multicolumn{4}{|c|}{ Kepusan pasien } & \multicolumn{2}{|c|}{ Total } & \multirow{3}{*}{$p$} \\
\hline & \multicolumn{2}{|c|}{ Baik } & \multicolumn{2}{|c|}{ Tidak baik } & \multirow[b]{2}{*}{$\mathrm{n}$} & \multirow[b]{2}{*}{$\%$} & \\
\hline & $\mathrm{n}$ & $\%$ & $\mathrm{n}$ & $\%$ & & & \\
\hline Baik & 69 & 86,3 & 11 & 13,8 & 80 & 100,0 & \\
\hline Tidak Baik & 8 & 53,3 & 7 & 46,7 & 15 & 100,0 & 0,007 \\
\hline Total & 77 & 81,1 & 18 & 18,9 & 95 & 100,00 & \\
\hline
\end{tabular}


Tabel 7. Distribusi Data Regresi antara Variabel Bukti Fisik, Tanggapan Jaminan, Emphaty terhadap Kepuasan Pasien di Puskesmas Maiwa.

\begin{tabular}{ccc}
\hline Kualitas & Tingkat signifikan & Standar cofisien \\
\hline Bukti fisik & 0,066 & 0,201 \\
Tanggapan & 0,419 & 0,84 \\
Jaminan & 0,017 & 0,269 \\
Empati & 0,388 & 0,091 \\
\hline
\end{tabular}

